\title{
Employees' Self-Cultural Integration Through Cultural Intelligence: A Case Of Finnish Firm
}

\author{
https://doi.org/10.21272/sec.4(2).32-43.2018
}

\author{
Shafaat Shafi \\ Master of Science in International Business, University of Oulu, Finland
}

\begin{abstract}
The paper analyses the culture's conceptual terrain from different scholarly perspectives, and how it has led to the emergence of different conceptualization of cultural intelligence. As such, cultural intelligence is described from the perspective of Earley et al.'s Thomas et al.'s and Plum's and then explained how Plum's conceptualization is a better construct to apply in the context of this paper and how it relates to the aims and objectives of this paper. The main purpose of the research is to see how cultural integration is enacted and carried out by foreign employees working in a firm that has completely different cultures from their own: the aim is to also see what factors or determinants form cultural intelligence.
\end{abstract}

The research methodology consists of conducting an open-ended interview with six employees who were working in a finish firm and they were asked questions based on how did they achieve their integration and went about their daily interactions and abstract situations. For analysis, Braun and Clarke' (2006) steps of thematic analysis were adopted for studying and analyzing the interviewed transcripts as their method of analyzing is based at constructing a narrative story out of the data.

The research proved what was assumed theoretically that culture is an evolving and negotiated social reality constructed by the social agents. The analysis part as result revealed that the daily interaction consists of the process of meaning-making complexities that lead to the evolvement of negotiated socio-cultural reality what we call cultural-integration on the part of employees.

As the world is going through a transformation in the midst of changes brought upon the unprecedented immigration and seamless borders, cross cultural interactions and cultural adaptability has become an extremely important issue. The results of this study have thus important implications for mangers and business leaders to take culture and integration as an evolving concept and as a journey as they try to integrate foreign employees or sending people abroad on expatriate mission.

Keywords: cultural intelligence, cultural integration, cross-cultural adjustment, self-integration.

JEL Classification: M14.

Cite as: Shafi, S. (2018). Employees' Self-Cultural Integration Through Cultural Intelligence: A Case Of Finnish Firm. SocioEconomic Challenges, 4(2), 32-43. https://doi.org/10.21272/sec.4(2).32-43.2018.

(C) The Authors, 2018. This article is published with open access at Sumy State University.

\section{Introduction}

The labor market is constantly changing amidst ever increasing globalization and the companies are recruiting people from across the cultures to cater to the technological demands and as a result, multicultural teams are an everyday organizational reality (Cox 1994; Galbraith 2000; Kirchmeyer \& McLellan 1991; Kirkman \& Shapiro 2001; Tung 1993). While cultural diversity is an advantage (Hancock \& Tyler 2007), this can prove to be liability as well leading to precious loss of resources (Joshi et al., 2002; Marquardt \& Horvath 2001; Matveev \& Nelson 2004), if employees fail to adjust themselves culturally. Organizations as such now look for employees who are culturally competent (Harvey \& Novicevic 2001). That is why cross-cultural adaptability skills has acquired so much significance in the multicultural world that employees need to decipher their immediate new cultural environment, an ability known as cultural intelligence.

This research essay is about cultural intelligence and how it is applied by foreign employees to achieve successful integration in their working environment or firms. Culture has often been defined and looked from the Hofstede's objectivist perspective. But this essay is making a shift from the mainstream perspective and employing constructivist perspective and in turn applying it in the conceptualization of cultural intelligence and seeing how foreign employees integrate themselves in their foreign firm. 
Cultural intelligence is defined as an ability to get along effectively across cultures and not allowing culture to stand as an impediment while working in an alien cultural environment. Integration has been described as to be dependent on the ability of the employees to successfully share their knowledge (Knowledge-sharing), acquiring an organizational trust and with no or minimal of conflicts. Integration as such assumes the meaning that the purpose for which employees have been hired is fulfilled and they are able to express and execute their skills thereby achieving job satisfaction and high performance without culture to be proving a damper in their efforts.

This study is positioned from the perspective of employees as they narrate their daily interactions as part of their strategy to derive meanings and interpret their surroundings in an attempt to integrate themselves culturally. This socio-cultural process of self-integration as new negotiated reality will be seen from the prism of cultural intelligence as to how it is applied in achieving that goal of cultural integration. This study's purpose is to dissect and present the process of integration in the context of Finnish firm where employees' daily interactions are presented from their narratives which can prove to be highly informed and educative for the prospective employees and businesses and cultural managers. The aim of the study is thus to see and present a detailed study on how cultural integration is achieved by the employees and what are the ingredients or determinants that help evolve and inform cultural intelligence. It will be seen what do the culturally intelligent people do differently and what and how do they gear events to their favor, and how their lives have gone on a different tangent that assist them in their integration in foreign cultures.

In order to streamline the focus of the reader to the purpose of the study, a research question is formulated in the following words:

\section{RQ1: How does cultural intelligence help foreign employees to manage their working lives across cultures?}

Also, during this research, it will be established how culture emerges as socially constructed phenomenon and negotiated reality of social agents, rather than pre-programmed deterministic phenomenon. Thus, it will also be seen how the process of integration is performed or enacted by the employees.

\section{Literature Review}

This literature review is aimed to serve as theoretical framework and readers will be explained as to how this research paper is theoretically on firm grounds as a result of previous literature study. Main concepts underpinning this study are presented to tailor the readers and research's focus.

\section{Culture and its interplay with Organizations}

Culture is an extremely fuzzy and multilayered concept and is highly contextual. That is why there is no universally agreed upon definition and scholars have opined that before describing culture it is important to lay the contextual ground for it. This is also the case in this research study as it describes culture to be a phenomenon that a person builds in order to make sense by deriving meanings and find a connection to the outer world. Culture, as was described earlier has been positioned from the constructivist standpoint as against the more mainstream and dominant essentialist understanding of culture. This changed view is dictated by the currents of globalization and the job market it is creating which is fittingly narrated by Søderberg \& Holden (2002): "based on shared or partly shared patterns of meaning and interpretation" (Søderberg \& Holden 2002: 112). And these or partly shared patterns are not something beyond change or immutable but in fact they are constructed, reconstructed and reformed and the boundaries of culture are malleable.

Organizations in this context has also been viewed from Morgan's (1997) understanding: "socially constructed realities based on communication and cognition of people in the organization". Taking constructivist framework in the context of integration Schein defines organizations as: "A pattern of basic assumptions, (b) invented, discovered, or developed by a given group, (c) as it learns to cope with its problems of external adaptation and internal integration, (d) that has worked well enough to be considered valid and, therefore (e) is to be taught to new members as the (f) correct way to perceive think, and feel in relation to those problems" (Schein 1990: 17).

Coming back to the cultural nuances, Scholars like Kleptesoo (1993), Geertz (1973), Alvesson (1995) as they critiqued the dominant positivistic view of culture and described culture in the constructivist sense as an evolving subjective social reality. As the limited scope and space of the study dictates a short explanation, it is thus judicious to quote Geertz as to how he explained his version of culture: 
"The concept of culture I espouse [...] is essentially a semiotic (meaning-making, Shafaat Shafi) one. Believing, with Max Weber, that man is an animal suspended in webs of significance he himself has spun, I take culture to be those webs, and the analysis of it to be therefore not an experimental science in search of law but an interpretative one in search of meaning. It is explication I am after" (Geertz 1973: 5).

That in simple words mean that culture is a something or a system that people utilize or adopts to derive meanings and sense of their immediate worlds that they find themselves in. This implies that while humans are influenced and shaped by culture, culture itself is shaped and molded by humans. As such, culture, according to Geertz as stated above is all about social and mental construction by the social actors.

Cultural Intelligence: As was described earlier, cultural intelligence is an ability that enables people to get along smoothly across cultures. It is unique cultural construct that has a targeted approach and is coherent and parsimonious in the sense that it focuses on the intercultural capabilities. It is parsimonious because it is clearer in its scope and space, that means it is aware as to what parts it possesses. It is also comprehensive in the sense that it covers abilities which other cultural constructs fail to consider. As such it is rich in its content and offers an academically fertile field of study with enormous practical implications. As such, it will be seen as to how it is applied by the social actors to derive meanings, interpret and craft a negotiated cultural reality in the firm. It is practical in the sense as it employs practical and actionable steps within the constructivist phraseology on how to be culturally competent. It will be interesting to see how foreign employees gear their unique cognition to achieve a new negotiated socio-cultural reality within their working environment.

Literature review shows that CQ has stood empirical test and has been proven extremely effective across cultures in terms of its effect on human behavior, psychology and performance (Ang et al., 2004). Matsumoto and Hwang (2013) reviewed 10 intercultural competency models as they singled out CQ to be the most efficient and effective cultural construct.

The three-dominant conceptualization of cultural intelligence happen to be Earley et al. (Thomas et al.'s (2003), Thomas (2006) and the approach of Plum (2008) represented as CI. These three narratives have enriched the theoretical and intellectual foundations of cultural intelligence. Earley et al. (2006) conceptualization of CQ happen to be the most dominant one in its empirical use (Early \& Peterson, 2004; Ang et al., 2006; Templer et al., Ang et al., 2007).

Earley et al.'s conceptualization of cultural intelligence: Earley et al. (2003) first introduced CQ as a concept as they set out to ascertain as to how some people are better able to adjust cross-culturally compared to others. They related cultural adjustment to flexibility thereby implying that CQ demands cognitive and behavioral flexibility. Hence their conceptualization of CQ consists of the following elements: "including what you think and how you solve problems (cultural strategic thinking); whether or not you are energized and persistent in your actions (motivation); and whether you can act in certain ways (behavior)" (Earley et al., 2006: 5). The three described elements according to Earley et al. were of similar nature but as the picture gives an impression that they are of different nature.

Given that culture is an exceedingly intermingled and overlapping construct, their representation of culture seems to be erratic. Their concept of culture and CQ is clearly rooted in the essentialist or objectivist cultural framework. This is not how CQ operates as behavior and motivation are coherent and interrelated concepts in the context of CQ. This is to say that CQ as a concept operates in a non-sequential manner and its final function is the subtotal of its ingredients. They further relate culturally intelligent behavior to an ability of people to mimic as they state: "Mimicry has generally positive effects in a social encounter. A high CQ-person is a talented mimic. By talented, we emphasize that this is not savant duplication, but a judicious use of similar actions and gestures to put another person at ease" (Earley et al., 2006: 34).

Research has shown that some mimicry does help (Byrne, 1971; Thomas, 2006) but taking it to long is bound to boomerang and is not a rational approach and it can lead to unwanted results (Giles \& Smith, 1979; Francis, 1991). It also amounts to rendering CQ as a shallow and simplistic concept.

Thomas et al.'s conceptualization of CQ: Though somewhat similar to Thomas et al.'s conceptualization of CQ, but they take a positivistic approach towards culture as is evident from their description: "a cultural map can be formed using one or several of the dimensions of cultural variation presently available” (e.g Hofstede 1980; Schwartz, 1994; Trompenaars, 1993). Their view of culture is more in line to the Hofstede and Trompenaars's view of culture. They tend to take collectivistic view of culture as if culture is homogenous entity and it does not have sub-cultures within it and as if all humans within a certain culture follows same behavioral acts and world view. This is lazy and fuzzy analysis culture and is against the concept of cultural 
integration. Such view of culture is also against CQ which is a malleable and fluid concept. Thomas et al.'s view thus cannot be prevailed and entertained in the standpoint of this paper which deals with culture as constructivist phenomenon.

Thomas et al. described CQ or culturally intelligent behavior as the function of cultural knowledge, cultural skills and cultural metacognition and they graphically represented these factors. They laid extra emphasis on the metacognition aspect of CQ as it is metacognition that plays the key role in enabling the person to process information and behave in a culturally intelligent way. The metacognition element of Thomas et al.' conceptualization of CQ relates to the intercultural engagement component of Plum's CQ. Thomas et al. view of CQ coheres with Earley et al.' view in the sense that both concepts argue for the cross-cultural adaptability or cultural integration to be the aim of CQ. But they also differ in the sense that according to Earley et.al, meta cognition elements provides flexibility of behavior and enables individuals to adopt new behaviors to fit in the new cultural surroundings.

Another glaring component missing in their conceptualization is motivation, as no matter how talented or skillful a person is, lack of motivation can be a major impediment. This is where Plum's view of CQ comes in to fill this missing gap.

\section{Plum's conceptualization of cultural intelligence (CI):}

Plum's concept of CI takes care of all the missing links of Earley et al.'s and Thomas et al.'s concepts of CQ and comes up with a comprehensive framework that incorporates a constructivist conception of culture. Plum's definition of CI takes the following form:

"The ability to make oneself understood and the ability to create a fruitful collaboration in situations where cultural differences play a role. It involves the ability to act in an appropriate way in multicultural situations coupled with the ability to have an open mind which admits new information and is curious about difference." (Plum, 2007b: 19).

The key element in the Plum's concept is the idea of self-awareness, an extremely critical and significant factor that enables a person to realize as to who he/she is and what are his/her thoughts and belief system. Plum takes a constructivist and an evolving notion of culture and thus fits in more with the idea of cultural integration. While Earley et al.'s and Thomas et al.'s describe culture as a measurable and quantifiable construct, Plum describes it as a "process between two people" which in turn prods her to describe it as "actual actions in a cultural meeting”.

This implies that Plum' CI is contextual and based on the interactions between people or groups of people and thus cannot be predicted and is fluid. Another difference is that the concept of CI is broader and is applicable to individuals, groups and organizations while CQ as a concept is predominantly geared towards individuals and national cultural differences.

Plum described CI as the function of three interrelated components which are namely intercultural engagement, cultural understanding and intercultural communication. Plum also takes motivation in to account and opines: "motivation implies a desire to create results together with people who are different from oneself". Pictorially, Plum's presented her view of CI as follows:

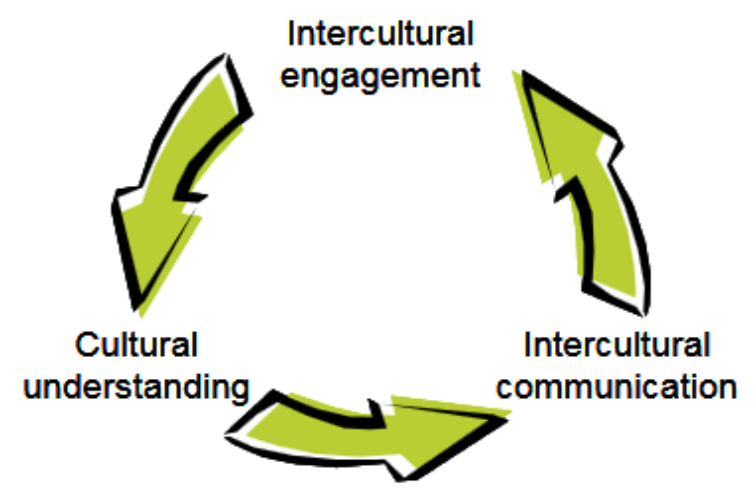

Figure 1. Plum's conceptualization of cultural intelligence (adapted from Plum, 2007b: 33). 
As the picture shows the three sub-dimensions influence each other and what we call cultural integrating through CI is a self-reinforcing and mutually dependent process. These sub dimensions are thus hard to demarcate and know as to what factors fall within what dimensions and what are the factors that caused failure in the integration process. These subdimensions are now further elaborated and delineate.

\section{a) Intercultural engagement}

This sub-dimension has motivation and emotional aspects as critical elements that push a person to know and understanding cultural world view of the other person in interaction and equips people to build bridges across cultures. How much significance Plum lends to this subdimension can be gauged from her description of it as "touch-paper" "the thing that changes fuel into fire and contains both the creative potential and the 'danger'; the positive driving forces and the stumbling blocks that can destroy or enliven the contact” (Plum, 2007: 81).

Emotional responses in the face of unexpected developing cultural encounter is important to avoid embarrassing and uncomfortable situations and to salvage an interaction. Plum also describes mental flexibility as important aspect as it enables one to change his behavioral pattern in order to adjust in the new cultural surroundings as dilates: "learning attitude, curiosity and the courage to allow [oneself] to be changed by the intercultural encounter" (Plum, 2008: 237). This means that person who is culturally competent has to store cultural signs emanating from the encounters and later apply them in a familiar situation as an attempt to achieve cultural integration and an expression of a person's cultural intelligence.

\section{b) Cultural understanding}

This subdimension deals with the "knowledge and mental dimension of CI" (Plum, 2008: 26) and is also known as cognition dimension of CI. Cultural self-awareness, general knowledge about the cultural differences and the ability to utilize and incorporate the acquired cultural experience into another such familiar cultural setting are the keys and main aspects of this dimension. Plum thus takes a cultural view of people's outlook, behaviors and their world view. It is true that people's behaviors and social acts cannot be predicted but a culturally knowledgeable and informed person can better maneuver and flow in culturally novel situations.

\section{c) Intercultural communication}

This is the third dimension in the Plum's conceptualization of CI and it has many aspects other than communication, and is the most important one to Plum as she describes it as the "cultural practice" and represents the actual action as to what takes place in a cultural encounter (Plum, 2008). Plum, contrary to Thomas et al view on CQ accords greater importance to action in her CI as she opines:

"It is the intercultural communication which brings the other two dimensions of cultural intelligence into the cultural encounter and creates contact between the parties. Cultural understanding which is not brought into play, or intercultural engagement which is not demonstrated, does not create results but remains unfulfilled (Plum, 2008: 29).”

Intercultural engagement factor demands that a person in order to achieve successful cultural integration must be aware of his/her communication style and the expressions inherent in that.

This means that culturally intelligent communication necessitates that a person must be self-aware of his/her communication style as well as of the cultural communication style of people involved in the cross-cultural encounters. Mere cultural knowledge of the opposing culture is not enough to achieve successful cross-cultural encounters, as techniques and skills to bridge the cultural differences are also required. An important part of intercultural communication also involves changing one' perspective and viewpoints on issues in the face of evolving situations. That in turn demands taking bold mental and cognitive steps as Plum describes it to have "the courage to experiment and take a new approach to the situation, to feel [one's] way and find 'new steps' (Plum, 2008).

All these three interrelated dimensions are important in making a person culturally intelligent and they form a structure which helps us to understand and improve our cross-cultural encounters. Cultural intelligence as such is the combination of these three dimensions and a culturally intelligent person all the three dimensions in some form. 


\section{Methodology}

The descriptive nature of the study and the ontological position vis-a-vis culture meant that open ended interview questions guided by CI were made. As a result, eight employees working in a Finnish firm were interviewed and open-ended questions were asked so that the in-depth discussion can be generated, and a subjective understanding of how cultural integration were sought and successfully achieved using their CI.

For analysis, Braun and Clarke' (2006) steps of thematic analysis were adopted for studying and analyzing the interviewed transcripts as their method of analyzing is based at constructing a narrative story out of the data. It was done by looking for patterns and meanings which then develops into broader themes and categories while keeping them within the context of the theoretical construct of this study. This meant that patterns and their projected meanings were categorized under the rubric of the sub dimensions of CI and subjective, constructivist narrative was derived out of it.

How Braun and Clarke’ (2006) steps were followed are provided below:

1. Becoming familiar with the data: The first step carried out as part of analysis was to read and re-read the data (interviews transcripts) in order to get a clear picture of it to prime it for further steps.

2. Generating initial codes: This phase will form the first order of coding in the table 2 given below. It consists of set of information that seemed relevant and important from the viewpoint of research questions while keeping the Plum's conceptualization of CQ in mind. An effort was made to look for codes that corresponds with the theoretical world view of this thesis and that serves the research objective of this thesis by answering research questions.

3. Searching for themes: In this step, after the creation of initial codes (first coding order), set of information that related to the research question and that seemed to be solving the research problem of understanding as to how the employees interpreted the social interactions in order to achieve integration, were patterned and condensed as themes. They were mostly generated out of the initial codes which entailed and constructed a meaning in line with the research theme of this thesis. These will be represented as the second order of coding in the table 2 .

4. Reviewing themes: This phase is represented as third order coding in the table 2. In this phase, an effort was made to make a broader categorization of the generated themes against the data set (interview data) to construct a convincing story which answers the research question of knowing the modus operandi of the foreign employee of social and cultural integration. These themes mostly concerned personality-based traits and the elements of CI that could serve as building blocks for the analysis.

5. Defining and naming themes: In this phase themes were analyzed, their scope described, their names decided, and a story was developed out of those themes. This step is represented as aggregate CI's dimensions in the table 1.

6. Producing the report: The final phase is developing an analytical narrative that fits in with the overall theoretical framework and the concepts discussed and reviewed.

Now that the analytical lens behind the findings has been laid out and explained, it is time to move to the actual codes and themes that emerged as result of it which were set against the Plum CI's determinants. Below is the table that represents how the different phases evolved in terms of codes and themes which will be later used for analysis.

Table 1. Emerged Codes/Themes and Dimensions

\begin{tabular}{|l|l|l|l|}
\hline \multicolumn{1}{|c|}{ Summarizing interview content (initial coding) Phase 2 } & $\begin{array}{c}\text { Names of Second } \\
\text { order of coding } \\
\text { (Phase 3) }\end{array}$ & $\begin{array}{c}\text { Names of Third } \\
\text { order coding } \\
\text { (Phase 4) }\end{array}$ & $\begin{array}{c}\text { Aggregate CI's } \\
\text { Dimension (Phase 5) }\end{array}$ \\
\hline $\begin{array}{l}\text { Change behavior according to the person's likes and } \\
\text { dislikes. No rigid behavior and being willing to adapt and } \\
\text { form new behaviors. }\end{array}$ & Adaptive behavior & $\begin{array}{l}\text { Malleable } \\
\text { personality }\end{array}$ & $\begin{array}{l}\text { Cultural } \\
\text { understanding }\end{array}$ \\
\hline $\begin{array}{l}\text { Collecting information and being alert and interest in } \\
\text { people and cultures, observing the behavior of people. }\end{array}$ & $\begin{array}{l}\text { Inquisitive } \\
\text { mindset/enriching } \\
\text { cultural experience }\end{array}$ & Cultural experience & $\begin{array}{l}\text { Cultural } \\
\text { understanding, } \\
\text { intercultural } \\
\text { engagement) }\end{array}$ \\
\hline
\end{tabular}


Table 1 (cont.). Emerged Codes/Themes and Dimensions

\begin{tabular}{|l|l|l|l|}
\hline \multicolumn{1}{|c|}{ Summarizing interview content (initial coding) Phase 2 } & $\begin{array}{l}\text { Names of Second } \\
\text { order of coding } \\
\text { (Phase 3) }\end{array}$ & $\begin{array}{l}\text { Names of Third } \\
\text { order coding } \\
\text { (Phase 4) }\end{array}$ & $\begin{array}{c}\text { Aggregate CI's } \\
\text { Dimension (Phase 5) }\end{array}$ \\
\hline $\begin{array}{l}\text { Culturally strategic Thinking individuals. } \\
\text { Connecting new information Planning, monitoring and } \\
\text { evaluating }\end{array}$ & Strategic thinkers & $\begin{array}{l}\text { subjective } \\
\text { construction of } \\
\text { reality/ Cultural } \\
\text { Informant }\end{array}$ & $\begin{array}{l}\text { CI (Cultural } \\
\text { understanding, } \\
\text { intercultural } \\
\text { experience) }\end{array}$ \\
\hline $\begin{array}{l}\text { I can do it attitude, not afraid of new situations and being } \\
\text { resilient, motivation, drive, tolerance for risk. }\end{array}$ & Self-efficacy & $\begin{array}{l}\text { Goal oriented } \\
\text { personality } \\
\text { disposition }\end{array}$ & $\begin{array}{l}\text { Cultural } \\
\text { understanding, } \\
\text { intercultural } \\
\text { experience) }\end{array}$ \\
\hline $\begin{array}{l}\text { Keen to learn new ideas, insights and flexible to change } \\
\text { opinions and assumptions if found not correct }\end{array}$ & $\begin{array}{l}\text { Thinking flexibility/ } \\
\text { Adaptive Thinking }\end{array}$ & $\begin{array}{l}\text { Personal } \\
\text { Characteristics/disp } \\
\text { ositions }\end{array}$ & $\begin{array}{l}\text { Cultural } \\
\text { understanding, } \\
\text { intercultural } \\
\text { experience }\end{array}$ \\
\hline $\begin{array}{l}\text { Learning language and switching between languages. } \\
\text { Active listener, quick learners, shared knowledge and } \\
\text { seeking mutual trust. }\end{array}$ & Communication & $\begin{array}{l}\text { Personality } \\
\text { characteristics/ } \\
\text { dispositions }\end{array}$ & $\begin{array}{l}\text { Intercultural } \\
\text { communication, } \\
\text { intercultural } \\
\text { engagement }\end{array}$ \\
\hline $\begin{array}{l}\text { Seeks collaborative solutions to problems, seeking } \\
\text { synergistic solutions. }\end{array}$ & $\begin{array}{l}\text { Relationship } \\
\text { builder/Manager/ } \\
\text { Integrationist } \\
\text { mindset }\end{array}$ & $\begin{array}{l}\text { Entercultural } \\
\text { Emotional } \\
\text { intelligence } \\
\text { intercultural } \\
\text { engagement }\end{array}$ \\
\hline
\end{tabular}

These emerged themes and broader categories provide building blocks and set the agenda for the analysis as they were reviewed against CI and its manifestations to see how cultural integration is performed by the employees. It is important to mention here that analysis is not done according to the order of the themes/categories or dimensions displayed here. The reason is that analysis takes its own flow and discourse that has submerged these themes and categories in its analysis whose purpose is to broaden the readers' understanding of the phenomenon of integration as processed by the employees using their cultural intelligence.

Further, as was mentioned earlier the sub-factors of CI are inextricably linked and are complimentary concepts and as such some of the concepts in the coding are interconnected and it was hard to separate them.

\section{Main Findings}

The findings are based on codes and themes that emerged based on the theoretical construct of the study which is the perspective of Plum's understanding of cultural intelligence. Employees working in the firm confirmed that they were feeling at home and felt that they have successfully achieved integration and are not feeling as outsiders, thus one can assume that they were cultural intelligent individuals and have achieved the set determinants of integration: trust and knowledge-sharing.

As the table shows many themes and patterns emerged and the following analysis will bear witness to it.

\section{Cross-cultural competence development}

Cultural competence development takes time to develop and is contingent upon on how the person takes forward his cultural journey and it was found that it depends on the following elements described below:

Acquiring cultural knowledge: It was found that acquiring cultural knowledge through interactions and living abroad can enhance and develop cultural intelligence and the person feel confident and no longer intimidated by the sudden change of cultural surroundings. The employees had lived in various countries and have been part of various cultures, as a result, their mental world view is so flexible and adjustable that they can be regarded as global citizens of the world. The narrative of their conversation reflects that expatriates like them live many lives simultaneously and are malleable bunch of individuals showing neurological and cognitive flexibility. For example, Employee 1 has spent 8 years in Finland, while Employee 2 has been abroad for 7 years now. This means that their learned cultural experiences enable them to think and decide on what world view to adopt when interacting with people of other cultures. That demands constant adjustments and readjustments on the part of employees in the face of emerging social reality and as the situation demands in order to achieve coherence with the interacting social agent. 
Moreover, all the interviewees had studied in Finland and have lived here for at least 4 years - an ample amount of time to raise one's awareness of host country's culture, before finding their workplace. The values and the world view that one learns and acquires as a result of spending time is, thus a crucial antecedent of formation of CI as our interviewee cases clearly demonstrated. None of them have started working at their firm right away after landing in Finland. As such, living in Finland has provided them a cultural platform that they used to adapt and integrate themselves in the Finnish firm.

Well-travelled individuals and inquisitive minded: Travelling enhances one's cultural experience and broadens people's world views by shattering their stereotypes that they have developed or formed over the years against other cultures and peoples. It causes and triggers the process of unleashing cultural understanding, intercultural engagement and intercultural communication as enshrined in the Plum's conceptualization of CI.

As a result, questions were asked to review their international and cultural exposure. It turned out that respondents had travelled extensively; they love knowing and learning about other countries, cultures and making friendships and networking. This has clearly raised their cultural awareness of different people and enhanced their cultural horizons. It also appeared from the interviews that these were individuals who were very keen observers and were marked by high inquisitiveness.

It can be therefore deduced that travelling abroad and learning about different cultures, have raised their cultural self-efficacy (motivation) which in turn, has made their cultural adjustment more manageable and achievable. I would here like to quote few of the statements from the interviewees to back this position advanced by the thesis:

Employee 1: "I would suggest that if you travel then it raises your self-confidence when it comes to dealing with new cultures. I would say integration in organization is far easier if you have already good experience of the culture of the country.

Employee 3: "For me integration comes after once you integrate in the culture and to integrate in the culture I feel you have to have cultural experience which you can gain by travelling abroad."

Language as catalyst for integration: The significance of language in integration can hardly be over emphasized. Learning a new language connotes cultural learning (Shannon \& Begley 2008; Harrison 2012) as language has the single greatest potential to trigger cultural learning (Alon \& Higgins 2005; Harrison 2012). It thus plays a huge part in the construction of new cultural identity (Jaspal 2009). This has been found to be the case in the employees of this firm; one thing that came out palpably clear was the effort on the part of foreign employees to learn and hone their Finnish skills as they spoke profusely about the significance Finnish language has in order to integrate or gain social and corporate cohesion with Finnish people.

Employee 6: "Once you start learning it, you will realize that you are starting to think like Finnish people (laughter....)”.

It came out that language enables one to adapt, construct and understand a subjective world in which to view himself/herself by arrogating meaning to their experience. All the interviewees thus emphasized the importance of learning the language and as such it came out as the common theme on which all of them strongly agreed as an important aspect of integration.

\section{Behavioural flexibility}

Plum (2008: 237) stated that cultural competence demands developing learning attitude, growing curiosity and "the courage to allow oneself to be changed by intercultural encounters". It was found from the interviews that employees' behaviors are marked by high flexibility. They reflected to have multiple behavioral alternatives at their disposal which they use as the situations dictate. This behavioral flexibility was quite remarkable and revelatory in the course of this research, as behaviors are often synonymous with rigidity and represent the social conditioning of individuals. But the interviewees stated that they have multiple behavioral designs and approaches for the workplace and also for different individuals. This as such enriches and enhances our understanding our cultural intelligence interviewees were unanimous in their views that that they shed their normal or typical behaviors when they encounter a particular situation or individual or group members. 


\section{Adaptive thinking}

It was found that $\mathrm{CI}$ is not all about adaptable or flexible behavioral only; in fact, thinking precedes behavior and represents the cultural understanding and intercultural engagement aspects of CI or cognition and metacognition of CQ.

Cultural intelligence demands going beyond one's own thinking and adopting new ways of thinking as it is the thinking that enables cognitive and behavioral flexibility and adaptability (Plum 2008). Perspective taking and not being judgmental appeared to be the dominant codes that the research categorized them in to adaptive thinking. It is believed that if thinking can be changed or transformed then the cultural values can also be changed or transformed, thereby, making the cultural integration a living and achievable social reality.

Employee 4: "The more you think about changing yourself, the better are your chances and if you practice it you can change yourself."

Employee 5: "If you think positively then you feel part of them and if you think negatively then you will never feel integrated. You have to think like you are part of them."

The concepts that help evolve such adaptive behavioral as per the data acquired are concept of self, linguistic relativity, and communication, all of which falls within the purview of cultural intelligence. Cross-cultural environments create such conditions and pushes one to an extent where flexibility becomes crucial for survival which these interviewees talked about and it seemed that they possessed it in abundance which allowed them to survive culturally.

\section{Concept of self - a hallmark of culturally intelligent person}

Plum in her understanding of CI states that a person must be aware of his own self which in turn can enable him to understand the other social actor as it can lessen the cultural foreignness and help a person maneuver the situation better. The data revealed that the interviewees were individuals that were aware of themselves as to who they are which I contend to call a concept of self-awareness which is a concept synonymous with the cultural understanding, intercultural engagement and intercultural communication as enunciated by Plum in her version of CI. Similarly, Earley et al. and Thomas et al. described CQ in terms of cognition, metacognition, behavioral and motivation, where the concept of self and or self-awareness on the part of culturally intelligent person appears evident. This thinking has been bolstered and corroborated by the interview data and it was visible from the interviewee statements that employees were individuals marked by high self-awareness. It is the ability and skills of knowing and being aware of yourself, your strengths and weaknesses in cultural terms.

\section{Self-efficacy:}

Self-efficacy represents the intercultural engagement element of CI or motivational sub-dimension of CQ or; it reflects the interest and self-drive of an individual in achieving cultural cohesion in a different cultural setting. In that regard, most of the interviewees expressed that they were confident and didn't allow any mental block to scare them or cause them stress. So, courtesy interviewed data, it was found that self-efficacy is highly connected to successful integration as it is all about the confidence one has to overcome cultural hurdles (MacNab \& Worthley 2012). It can thus be said that self-efficacy is a powerful ingredient and predictor of CQ.

\section{Conclusion and Discussion}

Now that the analysis has been conducted, it is aimed here to look at the research questions that were crafted and see how the findings seem to answer them.

To begin, the theoretical assumptions and standpoint have been emphatically vindicated beginning from the cultural viewpoint as the employees' daily social interactions confirm culture to be an experience lived (Hall 1983) and an evolving social reality. Plum (2008: 59) described culture as "a practice among people in a community and as a process, culture is a matter for negotiation among its members in different situations, and therefore under constant change". Such an image of cultural understanding emerges forcefully in the wake of interviewees' meaning making and interpretations. As such, the findings confirm and support the constructivist understanding of culture (Geertz, 1973; Kleppestø 1993; Alvesson, 1995) against a positivistic understanding (Hofstede, 1980; Trompenaars, 1993); culture emerged as a context-based phenomenon and a process rather than structure (Plum, 2008).

Culture integration in the context of the firm studied also comes out as a negotiated reality that is dependent on the daily interactions of social actors encompassing many external and environmental cultural forces. It 
emerged that what humans as social agents do and what they develop as social acts, impinge on what other social actors think, perceive and do in terms of social and behavioral acts. It is, as such a complex, intricate and fluid interaction of cognitive and behavioral adaptation of what is called as culture (Plum, 2008). And what emerges as a result of that complex social exchange is regarded as a negotiated cultural integration or culture. It appeared that sometimes employees are led by the social events and sometimes they lead the events and gear them towards the negotiated social reality as Max Weber narrated that man is a victim of the webs that he has spun around (Geertz, 1973: 5). What enables them to force events in their favor and how do they derive meaning and do interpretations is an ability and hallmark of high cultural intelligence which they have developed as result of years of cultural experience and socialization, their intentional urge and motivation to enhance the cultural understanding.

Cultural integration in context of this thesis was also based on developing mutual trust (Simpson, 2007; Aryee et al., 2002), lack of conflicts (Brett et al., 2006) and developing mechanism of knowledge-sharing (Riege, 2005). Interviewees were thus asked to describe their integration within the firm on those above-stated parameters which they stated that they have managed to achieve and there were no problems as such when it came to conflicts, achieving trust and knowledge-sharing. Also, they spoke satisfactorily about their job performance and satisfaction and thus it was assumed safely that the employees have successfully achieved their integration within the firm. It was quite revealing that the employees not only expressed thorough integration, but also insisted on carrying out and continuing to work for their employer, thereby, confirming that they are wellintegrated in their firm.

Hearing the meaning-based narratives of employees ascertained the applicability of CI in the cultural integration or CCA of foreign employees. It emerged that cultural understanding, intercultural engagement and intercultural communication as three sub-factors of Plum's conceptualization of CI are amply applied and embraced by the employees in order to steer themselves through cultural novelty and abstractness and resurrect a new socio-cultural reality within their organizations. Employees were thus marked by high cultural intelligence and they were well aware of their cultural standpoint, and they purposely and intentionally made efforts to reduce the cultural mismatch between them and the other employees in the manner as amply explained in the analysis part. The findings reveal how CI as cultural competence is informed, evolved and enriched through years of cross-cultural experiences and intercultural engagement and communication which make these foreign employees flexible on thinking and behavioral lines. It, as a result, came out evidently clear that enhanced and better CI's sub-dimensions result from years of cultural experiences.

As a result, at this point, after the construction of theoretical framework, emerged empirical data and the subsequent analysis, it is perhaps safe to say that this study has been able to answer RQ1.

As a result, based on these findings, it is self-evident that the research objective of this study as formulated through research question has been answered. The extensive and rigorousness of the analysis part lay bare how cultural understanding (cognitive), intercultural engagement and intercultural communication CI mix and impinge on the employees who then undertake integrative efforts. These integrative efforts can be seen in the efforts on the part of employees to learn Finnish language, interactions with locals and immersing themselves in Finnish culture. These efforts reinvigorate their cultural understanding, intercultural engagement and intercultural communication which raises their self-efficacy, which allows the room for flexibility of thinking and behaviors as they are influenced to suspend judgement.

Another vivid finding is that cultural integration is a work in progress and a journey rather than a destination. It requires constant tweaking of ones' behaviors and world-views to get along with the peers in order to stay integrative. This again, is in line with the constructivist theoretical stand undertaken in the study. And as the world is increasingly marked by high cultural diversity, CI will keep on attracting researchers and practitioners' imagination.

It was found that $\mathrm{CI}$ it operates and evolves in a way that is analogous to labyrinth. As labyrinth serves one to evolve, grow and change while reaching or achieving the target, same is the ability of CI. Just as labyrinth forces one to change course in the face of evolving situations, and just as labyrinth forces one to explore and discover new thinking patterns and strategies, CI has the same ability to force thinking flexibility which then ticks on and triggers behavioral flexibility while reaching the set goals. CI is thus a journey of self-discovery and psychological transformation as it enriches one's understanding of self and his/her place in the world and makes the journey fulfilling one. CI, therefore, enables and teaches one how to remain flexible in thoughts and 
behaviors as it demands rewiring of brain and reframing of cultural frames in the emergence of new cultural frames and new cultural realities. But it is also a journey of discovery of oneself and how to change oneself.

\section{Recommendations and Implications}

Every research while trying to answer some questions lays ground for further research avenues. Researchers have shown that cultural experience builds and reinforces CI. This research has also shown that while cultural experience did contribute to CI, but to what extent and how far, is something that future research could look in. Further, supplementary area of research could be why in some cases cultural experience fails to contribute to the development or enhancement of CI in a person.

Future research could also concentrate on the accumulation and how to learn CI as a learnable skill and ability. CI, therefore, offers rich diet for future intellectual sparring as it is highly dependent on the thinking and thought process as well as person's values, attitudes and belief systems that are formed over time and are therefore, difficult to change once they get embedded. For these reasons, the author believes that CI is still fertile in research pursuits

As many firms and corporations are now exceedingly incorporating cross-cultural training programs to speed up the integration and reduce the cultural stress, this study is an insightful document as it brings out the modus operandi of the foreign employees as to how do they go about their integration process and turn events in their favour. It shows how cultural challenges can be overcome by providing a detailed analysis and blueprint of interactions and interpretations of the social events by the employees. This study has thus important managerial and practical implications as it was found that cultural experience, language learning, building relationships, networks and open-mindedness are key elements for integration and developing cultural intelligence.

In a contemporary globalized world marked by high cultural diversity, CI's significance can hardly be overemphasized. CI as a cultural construct has assumed a universal validation and practicality transcending time and space.

\section{References}

1. Cox, T. (1994). Cultural diversity in organizations: Theory, research and practice. Berrett-Koehler Publishers.

2. Galbraith, J. R. (2000). Designing the global corporation. Jossey-Bass.

3. Kirchmeyer, C., \& McLellan, J. (1991). Capitalizing on ethnic diversity: An approach to managing the diverse workgroups of the 1990s. Canadian Journal of Administrative Sciences/Revue Canadienne des Sciences de l'Administration, 8(2), 72-79.

4. Kirkman, B. L., \& Shapiro, D. L. (2005). The impact of cultural value diversity on multicultural team performance. In Managing multinational teams: Global perspectives, 33-67. Emerald Group Publishing Limited.

5. Tung, R. L. (1993). Managing cross-national and intra-national diversity. Human Resource Management, 32(4), 461-477.

6. Hancock, P., \& Tyler, M. (2007). Un/doing gender and the aesthetics of organizational performance. Gender, Work \& Organization, 14(6), 512-533.

7. Joshi, A., Labianca, G., \& Caligiuri, P. M. (2002). Getting along long distance: Understanding conflict in a multinational team through network analysis. Journal of World Business, 37(4), 277-284.

8. Marquardt, M. J., \& Horvath, L. (2001). Global teams: How top multinationals span boundaries and cultures with high-speed teamwork. Nicholas Brealey Publishing.

9. Harvey, M., \& Novicevic, M. M. (2001). Selecting expatriates for increasingly complex global assignments. Career Development International, 6(2), 69-87.

10. Søderberg, A. M., \& Holden, N. (2002). Rethinking cross cultural management in a globalizing business world. International Journal of Cross Cultural Management, 2(1), 103-121.

11. Morgan, G., Gregory, F., \& Roach, C. (1997). Images of organization.

12. Schein, E. H. (1990). Organizational culture, 45(2), p. 109. American Psychological Association.

13. Kleppestø, S. (1993). Kultur och identitet vid företagsuppköp och fusioner. Nerenius \& Santérus förlag.

14. Geertz, G. (1973). The interpretation of cultures. New York: Basic Books.

15. Ang, S., Van Dyne, L., Koh, C., \& Ng, K. Y. (2004, August). The measurement of cultural intelligence. Academy of Management Meetings Symposium on Cultural Intelligence in the 21st Century, New Orleans, LA.

16. Matsumoto, D., \& Hwang, H. C. (2013). Assessing cross-cultural competence: A review of available tests. Journal of cross-cultural psychology, 44(6), 849-873. 
17. Earley, P. C., \& Ang, S. (2003). Cultural intelligence: Individual interactions across cultures. Stanford University Press.

18. Thomas, D. C. (2006). Domain and development of cultural intelligence: The importance of mindfulness. Group \& Organization Management, 31(1), 78-99.

19. Templer, K. J., Tay, C., \& Chandrasekar, N. A. (2006). Motivational cultural intelligence, realistic job preview, realistic living conditions preview, and cross-cultural adjustment. Group \& Organization Management, 31(1), 154-173.

20. Plum, E. (2008) CI: Cultural Intelligence: The art of leading cultural complexity. London: Middlesex University Press.

21. Byrne, D. (1971). The Attraction Paradigm, New York: Ac.

22. Hofstede, G. (1980). Motivation, leadership, and organization: do American theories apply abroad?. Organizational dynamics, 9(1), 42-63.

23. Schwartz, S. H. (1994). Beyond individualism/collectivism: New cultural dimensions of values. Sage Publications, Inc.

24. Trompenaars, F. (1993) Riding the Waves of Culture: Understanding Culture and Diversity in Business. London: Nicholas Brealey.

25. Braun, V., \& Clarke, V. (2006). Using thematic analysis in psychology. Qualitative research in psychology, 3(2), 77-101.

26. Shannon, L. M., \& Begley, T. M. (2008). Antecedents of four-factor model of cultural intelligence, 41-55. ME Sharpe.

27. Harrison, N. (2012). Investigating the impact of personality and early life experiences on intercultural interaction in internationalized universities. International Journal of Intercultural Relations, 36(2), 224-237.

28. Alon, I., \& Higgins, J. M. (2005). Global leadership success through emotional and cultural intelligences. Business Horizons, 48(6), 501-512.

29. Jaspal, R. (2009). Language and social identity: A psychosocial approach. Psych-Talk, 64, 17-20.

30. MacNab, B. R., \& Worthley, R. (2012). Individual characteristics as predictors of cultural intelligence development: The relevance of self-efficacy. International Journal of Intercultural Relations, 36(1), 62-71.

31. Simpson, T. W. (2012), What Is Trust? Pacific Philosophical Quarterly, 93: 587.

32. Aryee, S., Budhwar, P. S., \& Chen, Z. X. (2002). Trust as a mediator of the relationship between organizational justice and work outcomes: Test of a social exchange model. Journal of organizational Behavior, 23(3), 267-285.

33. Brett, J. M. (2007). Negotiating globally: How to negotiate deals, resolve disputes, and make decisions across cultural boundaries. John Wiley \& Sons.

34. Riege, A. (2005). Three-dozen knowledge-sharing barriers managers must consider. Journal of knowledge management, 9(3), 18-35. 